\title{
Fluorescent cooling of objects exposed to sunlight - the ruby example
}

\author{
Authors: Paul Berdahl, ${ }^{1 *}$ Sharon S. Chen, ${ }^{1}$ Hugo Destaillats, ${ }^{1}$ Thomas W. Kirchstetter, ${ }^{1}$ \\ Ronnen M. Levinson, ${ }^{1}$ and Michael A. Zalich ${ }^{2}$ \\ Affliations: \\ ${ }^{1}$ Heat Island Group, Energy Technologies Area, Lawrence Berkeley National Laboratory, \\ Berkeley, CA 94720, USA. \\ ${ }^{2}$ PPG Industries, Inc., Coatings Innovation Center, Allison Park, PA 15101, USA. \\ *Corresponding author, E-mail: paul.berdahl@gmail.com.
}

\begin{abstract}
Particularly in hot climates, various pigments are used to formulate desired non-white colors that stay cooler in the sun than alternatives. These cool pigments provide a high nearinfrared (NIR) reflectance in the solar infrared range of 700 to $2500 \mathrm{~nm}$, and also a color specified by a reflectance spectrum in the 400 to $700 \mathrm{~nm}$ visible range. Still cooler materials can be formulated by also utilizing the phenomenon of fluorescence (photoluminescence). Ruby, $\mathrm{Al}_{2} \mathrm{O}_{3}: \mathrm{Cr}$, is a prime example, with efficient emission in the deep red ( $\left.694 \mathrm{~nm}\right)$ and near infrared (700-800 nm). A layer of synthetic ruby crystals on a white surface having an attractive red color can remain cooler in the sun than conventional red materials. Ruby particles can also be used as a red/pink pigment. Increasing the $\mathrm{Cr}$ : $\mathrm{Al}$ ratio produces a stronger (darker) pigment but doping above $\sim 3 \mathrm{wt} \% \mathrm{Cr}_{2} \mathrm{O}_{3}$ causes concentration quenching of the fluorescence. The system quantum efficiency for lightly doped ruby-pigmented coatings over white is high, $0.83 \pm 0.10$.
\end{abstract}

\section{Introduction}

The purpose of this paper is to introduce a novel method for reducing the temperature of (nonwhite) colored materials exposed to sunlight, by utilizing the phenomenon of fluorescence. In order to illustrate the principle, we use the example of chromium-doped aluminum oxide, i.e., ruby. Of course, it is well known that fluorescent emission transports radiant energy, but its application to reduce the temperature of objects exposed to sunlight is novel.

There are a number of applications in which it is desirable to reject solar heat. These include building envelopes (roofs, walls, etc.) to reduce air conditioning energy use [1-4]. A similar need occurs if materials such as vinyl plastics can be damaged by excessive heat. Automobiles in hot climates likewise benefit from minimizing solar heating [5]. Further uses are cooling instrumentation enclosures and storage tanks, and cooling ships and military vehicles to reduce their thermal radiation signature [6)]. Cool roofing is a key application and a focus of this paper. 

beneficial. If some of the solar flux cannot be reflected, then high thermal-infrared emittance and efficient convective cooling are desired. White coatings have suitable solar reflectance and thermal emittance properties, and are appropriate for many applications. On the other hand for aesthetic reasons (or for camouflage) white or other light colors may not be suitable. Building energy codes may require cool roofing. However, manufacturers of roofing materials are then faced with a palette of mostly pastel colors not attractive for their customers. For this reason "cool" colors are needed.

Over the past several decades, cool colored roofing has increased in popularity. For the materials designers, the problem has been to match a desired color (spectral reflectance in the 400 to $700 \mathrm{~nm}$ visible range) while maximizing solar reflectance. This has been done mainly by minimizing absorption in the solar near-infrared range (NIR, ca. 700 to $2500 \mathrm{~nm}$ ) [7,8]. Thus non-selective blacks such as carbon black and iron oxide magnetite black are omitted from recipes, and selective blacks such as mixed metal oxides of iron and chromium are used. In the NIR, the selective blacks have lower absorptance and also fairly high reflectance. Durable and cool pigments are available in a variety of colors, mainly based on inorganic mixed oxides containing transition metals. Some organic pigments are also useful and produce vivid colors. However the cost and durability of organics are limitations.

The modern strategy of color combined with high-NIR reflectance is effective but passive. Even higher performance is possible by utilizing the active phenomenon of fluorescence. Absorbed photons will not only produce heat but also cause fluorescence.

A prototypical fluorescent material is ruby, aluminum oxide doped with chromium. When lightly doped ruby is excited with ultraviolet (UV) or visible light, it fluoresces at 692.9 and $694.3 \mathrm{~nm}$, a doublet called the R-lines [9]. The absorption strength is weak in the red part of the spectrum, and also weak in the blue. Thus the color of ruby varies from pink at low doping to a bluish red as more chromium is added. At high concentrations of chromium (ca. 1\%), an additional emission spectrum extending from about 655 to beyond $800 \mathrm{~nm}$ is particularly apparent [10-13]. The 700-800 $\mathrm{nm}$ emission is thought to be due to neighboring pairs and possibly other clusters, of $\mathrm{Cr}^{3+}$ ions. At higher doping, first the R-lines are extinguished (concentration quenching), and then the additional spectrum also fades away.

Ruby certainly has remarkable optical properties. The first optical laser was fabricated from a lightly doped ruby crystal with silvered end faces, exposed to the light from a flash lamp [9]. Also, the spectral shift of the fluorescent $R$ lines is used to measure pressure [14] and the brightness and decay time can be used to measure temperature [15].

As a first experiment to verify the cooling due to ruby fluorescence, inexpensive commercial synthetic ruby gems were employed. An array of square pyramidal crystals was attached to a bright white substrate $\left(\mathrm{TiO}_{2}\right.$ pigmented coating) using a transparent acrylic overcoat. An off- 
white sample with a calibrated solar reflectance of 0.65 was used for comparison. Both samples were mounted on an insulating substrate and exposed to full sunlight on a clear day. The reference sample's temperature was $21.3^{\circ} \mathrm{C}$ above air temperature whereas the ruby-covered sample was only $14.8{ }^{\circ} \mathrm{C}$ above air temperature. Therefore the effective solar reflectance (ESR) (corrected for some exposed substrate) was larger than 0.65 , and estimated to be about 0.71 . (Effective solar reflectance is the fraction of incident solar energy that is rejected by reflectance and fluorescence. Additional, more complete, measurements on another ruby-crystal-covered substrate are reported below.) Thus the concept of utilizing chromium-doped alumina to provide reddish colors that are cool in the sun seemed worthy of further investigation.

\section{Performance of array of synthetic ruby crystals}

Polished ruby crystals intended for the jewelry industry were purchased from a commercial supplier. The cost was about 60 USD per lot of 200 crystals. The footprint of each crystal is a 5 $\mathrm{mm}$ x $5 \mathrm{~mm}$ square with a chamfered pyramidal shape about $2.6 \mathrm{~mm}$ high. A $75 \mathrm{~mm}$ square aluminum substrate was coated with 3 layers of an acrylic white paint. The crystals were arranged in a square array to cover the substrate and coated with two coats of clear acrylic. The white underlay enhances absorption of excitation light that may pass through the ruby and also reflects fluorescent emission that strikes the substrate. The clear acrylic coating holds the crystals in place and also raises the thermal emittance to 0.89 from 0.71 . Figure 1 (A) shows the appearance of the crystal array in full sun; the red color is dark, having reflectance in the center of the visual range at $550 \mathrm{~nm}$ of only 0.044 . The fluorescence is not visible in Fig. 1(A) because the camera (and eye) is not very sensitive at $694 \mathrm{~nm}$ and is completely insensitive in the 700 to 800 NIR range. Fig. 1 (B) shows the glow of the array at 694 (and $655-700$ ) nm when excited by UV in the dark. The fluorescence tends to emerge from the edges of the crystals.

Temperature measurements in full sun were used to estimate the effective solar absorptance of the crystal array and, by subtracting from unity, its effective solar reflectance. Temperature rise in the sun is roughly proportional to solar absorptance. Calibrated non-fluorescent gray and white samples were used for comparison, as was a reference ruby array over-coated with an opaque white paint. The white array was used to check that convective cooling was not unduly enhanced by surface roughness. A first estimate, made by interpolating between calibrated gray and white samples, yielded an effective absorptance of 0.262. A second estimate used the white-coated ruby crystal array as a reference, and employed estimates of the solar flux (1050 W $\mathrm{m}^{-2}$ ) and of the longwave radiative cooling of a blackbody emitter, referred to ambient air temperature $\left(70 \mathrm{~W} \mathrm{~m}^{-2}\right)$, to infer the sum of the radiative and convective heat transfer coefficients of $h_{\mathrm{r}}+h_{\mathrm{c}}=14.7 \mathrm{~W} \mathrm{~m}^{-2} \mathrm{~K}^{-1}$. These coefficients were then used to compute the effective solar absorptance of the ruby crystal array as 0.264 . Averaging the two estimates of absorptance and subtracting from unity yields ESR $=0.737 \pm 0.010$. Spectrometer measurement, excluding the fluorescence, yields solar reflectance $S R=0.434$. Thus the fluorescence contribution ("boost"), the difference ESR-SR, is about 0.30 ; the fluorescent energy flux is over $300 \mathrm{~W} \mathrm{~m}^{-2}$. The ruby 
array is as cool in the sun as typical white commercial materials with SR in the range of [0.65, $0.85]$, but is quite visually dark.

\section{Combustion synthesis of ruby powder}

The combustion synthesis method of Kingsley and Patil [16] was chosen as a convenient method for synthesizing small quantities of ruby powder with various chromium concentrations. Briefly, hydrated nitrates of aluminum and chromium are dissolved in water, as is sufficient urea (fuel) for a combustion reaction. A glass beaker containing the solution is placed in a $500{ }^{\circ} \mathrm{C}$ furnace. After boiling for several minutes, the dehydrated solution ignites for several seconds. What remains in the beaker is a fluffy pink product consisting of $\mathrm{Al}_{2} \mathrm{O}_{3}: \mathrm{Cr}$. The yield is $\sim 95 \%$ crystalline $\alpha$-phase alumina with $\gamma$-phase alumina as a second phase. The $\mathrm{Cr}$ doped $\gamma$ phase is easily identified as its color is not pink. Depending on the $\mathrm{Cr}$ concentration, this phase is green, yellow or white [17]. The unwanted $\gamma$ phase was physically removed, although we also verified that annealing it at $1200{ }^{\circ} \mathrm{C}$ for two hours in air can convert it to the $\alpha$ phase.

In preparing various ruby powders, we found that some excess fuel improved preparation of larger lots. Further, higher furnace temperatures were beneficial for higher $\mathrm{Cr}$ doping. The combustion process is more rapid at higher furnace temperatures, though if it is too fast the product is dispersed inside the furnace.

$\mathrm{X}$-ray fluorescence (XRF) verified the expected chromium concentration for two of the samples $(1 \%, 3 \%)$. (In this paper, we express the doping by means of $w$, the weight fraction of $\mathrm{Cr}_{2} \mathrm{O}_{3}$ in $\mathrm{Al}_{2} \mathrm{O}_{3}$. A common alternative is to use $x$, the ratio of numbers of $\mathrm{Cr}$ to $\mathrm{Al}$ atoms; $x=0.67 w$.). BET-measured surface area varied considerably from run to run, with typical values of $1 \mathrm{~m}^{2} \mathrm{~g}^{-1}$, ranging up to $11 \mathrm{~m}^{2} \mathrm{~g}^{-1}$ with higher furnace temperatures. Electron micrographs (Fig. 2) show slab-like particles with typical thickness of 2 to $5 \mu \mathrm{m}$. The morphology is likely a replica of the walls of foam just prior to combustion. After each synthesis a small UV lamp was used to visually check for the expected red fluorescence. X-ray diffraction also was used to verify that the observed peaks are those of the $\alpha$ phase of alumina.

To measure optical properties, the powders were mixed with a transparent acrylic paint using a spatula on a smooth glass surface, and spread as a $\sim 500 \mu \mathrm{m}$ coating onto a white substrate (75 $\mathrm{mm}$ square of aluminum with three coats of an artists' titanium dioxide white). This process is crude but simple. About $3 \mathrm{~g}$ of pigment was used in each coating. In what follows, the coatings are identified by the weight fraction of chromium oxide in the alumina pigment: $0.0 \% 0.2 \%, 1 \%$, $2 \%, 3 \%$, and $4 \%$.

\section{Spectral fluorescence and Effective Solar Reflectance (ESR)}

The optical setup included a $6 \mathrm{~V}$ lamp (tungsten filament, xenon gas fill), a filter to block excitation light in the spectral range of emission, a $150 \mathrm{~mm}$ integrating sphere, and an Ocean 
Optics spectrometer with silicon array detector. The spectrometer was calibrated using the tungsten lamp filament as a reference at an assumed temperature of $3000 \mathrm{~K}$.

Figure 3 shows the spectral emission of the ruby-pigmented coatings and the crystal array. Comparable data for two ruby crystals may be found in [12]. The sharp peak at $694 \mathrm{~nm}$ is highest in the low concentration samples $(0.2 \%, 1 \%)$ and diminishes monotonically with higher doping. Particularly at higher doping, emission ranges all the way from 655 to $\sim 800 \mathrm{~nm}$.

ESR measurements were performed on each of the $75 \mathrm{~mm}$ square samples by placing them on a thermally insulating substrate in full sunlight, next to calibrated non-fluorescent white and light gray samples of known solar reflectance (SR). Thermistors underneath the samples determined the temperatures, and the ESR values were then determined by interpolation. For comparison, the regular SR was determined with a Perkin Elmer Lambda 900 spectrometer fitted with a 150 mm integrating sphere. A standard solar spectrum for clear sky conditions with the sun high in the sky was used as a weighting function [18]. The short-wave part of the spectrum was detected with a photomultiplier tube (out to $\sim 860 \mathrm{~nm}$ ), and the long-wave part was detected with a $\mathrm{PbS}$ semiconductor detector. Now, the ruby fluorescence interferes slightly with the reflectance measurement since, for example, when the sample is illuminated with blue light it reflects blue light but also glows with red and near-infrared light detected by the phototube. For this reason, we used an interference filter placed over the phototube to greatly reduce its sensitivity to red and near infrared light. This filter allowed us to measure the reflectance spectrum excluding the fluorescence. Measurements without the filter then allowed us to evaluate the reflectance correction needed to account for fluorescence. This correction had the spectral shape of the wellknown ruby excitation spectrum [9] and was largest at 0.081 at $560 \mathrm{~nm}$ for the $1 \%$ sample. The ESR results for the ruby pigmented coatings are shown in Fig. 4, along with SR measurements and reflectance at $550 \mathrm{~nm}$. These coatings are not as dark as the ruby crystal array but nonetheless exhibit a fluorescence contribution (ESR-SR) of up to 0.16 .

\section{Determination of quantum efficiency}

It is assumed that all of the photons not reflected in the UV and the 400 to $700 \mathrm{~nm}$ visible range are absorbed by $\mathrm{Cr}^{3+}$ ions. This approximation is based on the idea that other weak absorption centers present, for example in the undoped $\mathrm{Al}_{2} \mathrm{O}_{3}$ sample, are not able to successfully compete for photons with the chromium ions. Particularly in the 650 to $700 \mathrm{~nm}$ range the $\mathrm{Cr}^{3+}$ absorption may be slightly overestimated. Beyond $700 \mathrm{~nm}$, there is still some absorption but it is relatively weak and will be neglected (Fig. 5).

The reflectance spectra in Fig. 5 show the two sharp absorption dips corresponding to the main ruby emission lines, and also some features at longer wavelength. This structure is a consequence of time reversal invariance, in that photon emission processes can proceed in reverse, causing absorption. Also, it is interesting that the baselines in this figure are lower with 


\begin{tabular}{|l|l|l|l|l|l|l|}
\hline Sample & $\begin{array}{l}\mathrm{Cr}_{2} \mathrm{O}_{3} \\
\text { content } \\
\left(\begin{array}{l}\mathrm{Al}_{2} \text { in } \\
\left.\mathrm{A}_{2}\right)_{3}\end{array}\right.\end{array}$ & $\begin{array}{l}\text { Reflectance } \\
\text { at 550 } \mathrm{nm}\end{array}$ & $\begin{array}{l}\text { Effective } \\
\text { Solar } \\
\text { Reflectance } \\
(\text { ESR })\end{array}$ & $\begin{array}{l}\text { Fluorescence } \\
\text { Contribution, } \\
\text { (ESR-SR) }\end{array}$ & $\begin{array}{l}\text { Energy } \\
\text { efficiency }\end{array}$ & $\begin{array}{l}\text { Quantum } \\
\text { efficiency }\end{array}$ \\
\hline $\begin{array}{l}\text { Crystal } \\
\text { array 1 }\end{array}$ & $\sim 0.9$ & 0.04 & 0.706 & 0.293 & 0.70 & 0.95 \\
\hline $\begin{array}{l}\text { Crystal } \\
\text { array 2 }\end{array}$ & $\sim 0.9$ & 0.044 & 0.737 & 0.303 & 0.72 & 0.98 \\
\hline Coating & 0.0 & 0.923 & 0.828 & 0.00 & 0 & 0 \\
\hline Coating & 0.2 & 0.540 & 0.824 & 0.092 & 0.56 & 0.93 \\
\hline Coating & 1 & 0.366 & 0.807 & 0.128 & 0.55 & 0.74 \\
\hline Coating & 2 & 0.301 & 0.805 & 0.165 & 0.62 & 0.83 \\
\hline Coating & 3 & 0.261 & 0.780 & 0.154 & 0.56 & 0.74 \\
\hline Coating & 4 & 0.203 & 0.637 & 0.049 & 0.16 & 0.21 \\
\hline
\end{tabular}

Table 1. Performance of eight samples. Visual reflectance, ESR, ESR-SR, energy efficiency, and quantum efficiency.

The white substrate has a reflectance of about 0.933 at $700 \mathrm{~nm}$. Since half of the photons are emitted toward the substrate, the highest possible system quantum efficiency is about 0.97 . Thus the crystal arrays have very high quantum efficiencies, and the films pigmented with ruby are in the range of $0.83 \pm 0.10$ for doping $\leq 3 \%$. The relatively large uncertainty in the quantum efficiency is believed to reflect experimental errors in ESR of roughly 0.01 . By $4 \%$, the quantum efficiency decreases dramatically to 0.21 .

\section{Limitations of ruby powder as a red pigment}

We have shown that doping above $3 \%$ of $\mathrm{Cr}_{2} \mathrm{O}_{3}$ leads to much reduced fluorescence. If we elect to use $3 \%$ or less dopant, the absorption strength of the pigment is limited. The average optical absorption cross section of the $\mathrm{Cr}^{3+}$ ion in the portion of the solar spectrum absorbed by ruby is roughly $1 \times 10^{19} \mathrm{~cm}^{-2}$ [9]. The concentration of ions at $3 \%$ is $\sim 6 \times 10^{20} \mathrm{~cm}^{-3}$. For the product of these numbers and the layer thickness $d$ to be unity, $d \sim 160 \mu \mathrm{m}$. Now some commercial coatings (paints) are as thin as $20 \mu \mathrm{m}$, so it is clear that the ruby pigments are "weak." In 
commercial coatings applications, maximum pigment volume concentrations are on the order of $50 \%$, which would require twice the film thickness. On the other hand, efficient use of the fluorescence requires a reflective underlayer, which halves the needed thickness. Further, introduction of some scattering may enhance absorption efficiency at the expense of a lighter color. However, the main point is that the limited pigment tinting strength is an issue in applications in which film thickness is constrained.

The color of the coatings studied here range from light red to pink, in contrast to the darker array of ruby crystals. The reason is light scattering due to the difference in ruby refractive index $(\sim 1.76)$ and that of the polymer medium $(\sim 1.5)$. Reduction of light scattering can be obtained by using larger particles, with fewer interfaces per unit volume, or by using nanoparticles with diameters well below $100 \mathrm{~nm}$. Also, the medium can possibly be engineered to have a high and matching refractive index (scattering is proportional to the square of the difference in refractive indices).

Finally, we point out that aluminum oxide particles are hard and abrasive, so care is required to avoid damage to coating manufacturing equipment.

\section{Fluorescent pigments other than ruby}

While the fluorescence of ruby is remarkable, with high quantum efficiency, our example is not unique. Other solid-state laser materials like Nd-doped YAG (yttrium aluminum garnet) are obvious possibilities. The study of IR fluorescence in historical pigments [20] has shown that the cadmium pigments CdS, CdSe and their alloys fluoresce [21], as do some alkali earth copper silicates $[22,23]$ such as Egyptian blue $\left(\mathrm{CaCuSi}_{4} \mathrm{O}_{10}\right)$ and $\mathrm{Han}$ blue $\left(\mathrm{BaCuSi}_{4} \mathrm{O}_{10}\right)$. Decades of research on phosphors for color television, for mercury-vapor fluorescent lamps, and more recently for light emitting diodes, has led to a wide variety of efficient compounds that fluoresce in the visible $[24,25]$. Doubtless some of these compounds can be modified for emission in the near infrared. Further candidate materials for NIR fluorescence may be found in sister applications. These include pigments for labeling, including nanoparticles for biological applications, direct-bandgap semiconductors considered for photovoltaics, and chromophores for application in fluorescent solar concentrators [26, 27].

For applications to cooling of sunlit materials, beyond fluorescence, we need interesting color, compatibility with high NIR reflectance, durability, and minimal toxicity.

\section{Summary}

In summary, we have introduced the idea of utilizing fluorescence to reduce the temperature of objects in sunlight, using ruby as an example. We have also used temperature measurements in sunlight, together with spectral measurements of reflectance and fluorescence, to determine the quantum efficiency of the fluorescence process. 


\section{Acknowledgments}

M. L. Shiao pointed out to P. B. that innovation in cool roofing materials is needed. Colleagues at Shepherd Color (S. Boocock, J. Peake) advised us on solid-state synthesis of mixed metal oxide pigments. We thank M. Levitus of Arizona State University for assistance with early fluorescence measurements, X. Song of the LBNL electrochemistry group for assistance with BET measurements, N. Bronstein of University of California at Berkeley for bringing Refs. 26 and 27 to our attention, and D. McHenry of PPG Industries for XRF measurements.

This work was supported by the Assistant Secretary for Energy Efficiency and Renewable Energy, Building Technologies Office of the US Department of Energy under Contract No. DEAC02-05CH11231. Additional support was provided by the California Energy Commission under Agreement EPC-14-010.

\section{References}

1. J. A. Reagan and D. M. Acklam, Solar reflectivity of common building materials and its influence on the roof heat gain of typical southwestern USA residences, Energy \& Buildings 2, 237-248 (1979).

2. A. H. Rosenfeld, H. Akbari, J. J. Romm, and M. Pomerantz, Cool communities: strategies for heat island mitigation and smog reduction, Energy \& Buildings 28, 51-62 (1998).

3. M. Pomerantz, H. Akbari, P. Berdahl, S. J. Konopacki, H. Taha, and A. H. Rosenfeld, Reflective surfaces for cooler buildings and cities, Philosophical Magazine Part B 79, 14571476 (1999).

4. H. Akbari, R. Levinson, L. Rainer, Monitoring the energy-use effects of cool roofs on California commercial buildings, Energy \& Buildings 37, 1007-1016 (2005).

5. R. Levinson, H. Pan, G. Ban-Weiss, P. Rosado, R. Paolini, and H. Akbari, Potential benefits of solar reflective car shells: cooler cabins, fuel savings and emission reductions, Applied Energy 88, 4343-4357 (2011).

6. R. F. Brady and L. V. Wake, Principles and formulations for organic coatings with tailored infrared properties, Prog. in Organic Coatings 20, 1-25 (1992).

7. R. Levinson, P. Berdahl, H. Akbari, W. Miller, I. Joedicke, J. Reilly, Y. Suzuki, and M. Vondran, Methods of creating solar-reflective nonwhite surfaces and their applications to residential roofing materials, Solar Energy Materials and Solar Cells 91, 304-314 (2007).

8. R. Levinson, P. Berdahl, and H. Akbari, Solar spectral optical properties of pigments, Parts I and II, Solar Energy Materials and Solar Cells 89, 319-349 and 351-389 (2005). 
9. T. H. Maiman, R. H. Hoskins, I. J. D’Haenens, C. K. Asawa, and V. Evtuhov, Stimulated optical emission in fluorescent solids. II. Spectroscopy and stimulated emission in ruby, Phys. Rev. 123, 1151-1157 (1961).

10. N. A. Tolstoi, Liu Shun'-fu, and M. E. Lapidus, The luminescence kinetics of chromium luminophors. III. Ruby, Optics \& Spectroscopy 13, \#2, 133-136 (1962).

11. A. L. Schawlow, D. L. Wood, and A. M. Clogston, Electronic spectra of exchange-coupled ion pairs in crystals, Phys. Rev. Lett. 3, 271-273 (1959).

12. R. C. Powell, B. DiBartolo, B. Birang and C. S. Naiman, Fluorescence studies of energy transfer between single and pair $\mathrm{Cr}^{3+}$ systems in $\mathrm{Al}_{2} \mathrm{O}_{3}$, Phys. Rev. 155, 299-308 (1967).

13. R. C. Powell and B. DiBartolo, Optical properties of heavily doped ruby, Phys. Stat. Sol. (a) 10, 315-357 (1972).

14. J. D. Barnett, S. Block, and G. J. Piermarini, An optical fluorescence system for quantitative pressure measurement in the diamond-anvil cell, Rev. Sci. Instruments 44, 1-9 (1973).

15. C. Pflitsch, R. A. Siddiqui, and B. Atakan, Phosphorescence properties of sol-gel derived ruby measured as functions of temperature and $\mathrm{Cr}^{3+}$ content, Appl. Phys. A 90, 527-532 (2008).

16. J. J. Kingsley and K. C. Patil, A novel combustion process for the synthesis of fine particle $\alpha$-alumina and related oxide materials, Materials Letters 6, 427-432 (1988).

17. S. Cava, R. Beninca, S. M. Tebcherani, I. A. Souza, C. A. Paskocimas, E. Longo, and J. A. Varela, Structural and spectroscopic characterization of $\mathrm{Al}_{2-\mathrm{x}} \mathrm{Cr}_{\mathrm{x}} \mathrm{O}_{3}$ powders obtained by polymeric precursor method, J. Sol-Gel Sci. Techn. 43, 131-136 (2007).

18. R. Levinson, H. Akbari, P. Berdahl, Measuring solar reflectance - part I: defining a metric that accurately predicts solar heat gain, Solar Energy 84, 1717-1744 (2010).

19. C. Wang and Z Zhao, Transparent polycrystalline ruby ceramic by spark plasma sintering, Materials Research Bulletin 45, 1127-1131 (2010).

20. A. Romani, C. Clementi, C. Miliani, and G. Favaro, Fluorescence spectroscopy: a powerful technique for noninvasive characterization of artwork, Accounts of Chemical Research 43, 837846 (2010).

21. M. Thoury, J. K. Delaney, E. Rene de la Rie, M. Palmer, K. Morales, and J. Krueger, Nearinfrared luminescence of cadmium pigments: in situ identification and mapping in paintings, Appl. Spectroscopy 65, 939-951 (2011). 
22. G. Pozza, D. Ajo, G. Chiari, F. De Zuane, and M. Favaro, Photoluminescence of the inorganic pigments, Egyptian Blue, Han blue, and Han purple, J. of Cultural Heritage 1, 393-398 (2000).

23. G. Accorsi, G. Verri, M. Bolognesi, N. Armaroli, C. Clementi, and Aldo Romani, The exceptional near-infrared luminescence properties of cuprorivaite (Egyptian blue), Chem. Commun. 3392-3394 (2009).

24. W. M. Yen and M. J Weber, Inorganic phosphors: compositions, preparation, and optical properties, CRC Press, Boca Raton, Florida 33487 USA (2004)

25. W. M. Yen, S. Shionoya, and H. Yamamoto, eds., Fundamentals of phosphors, CRC Press, Taylor and Francis Group, Boca Raton, Florida 33487 USA (2007).

26. P. S. Friedman and C. R. Parent, Luminescent solar concentrator development, project report SERI/STR-211-3149 for the Solar Energy Research Institute (1087).

27. M. G. Devije and P. P. C. Verbunt, Thirty years of luminescent solar concentrator research: solar energy for the built environment, Adv. Energy Mater. 2, 12-35 (2012).

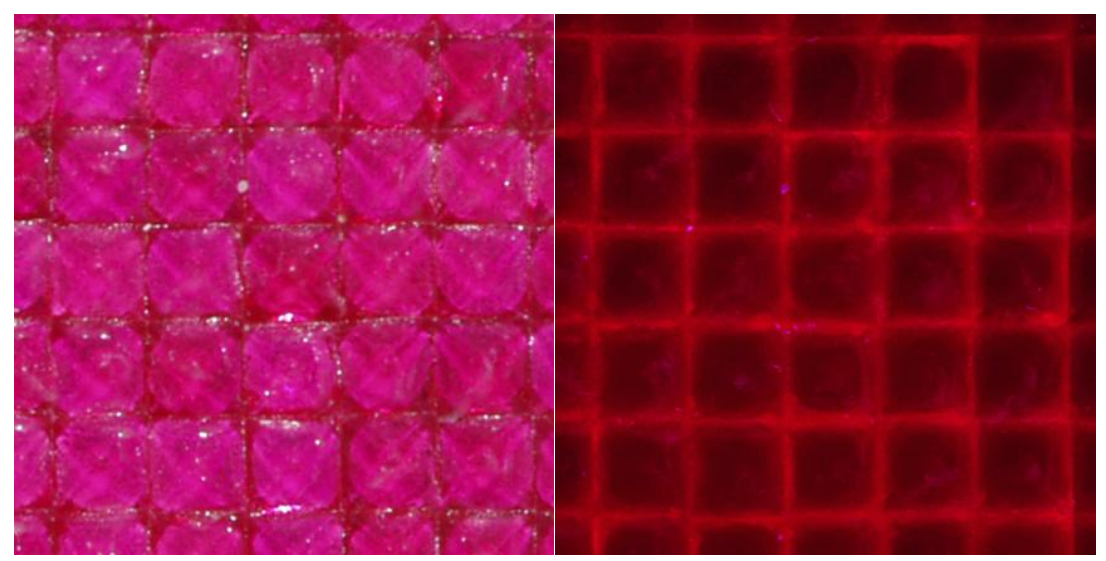

(A)

(B)

Fig. 1. Photographs of a portion of the ruby crystal array (A) in sunlight (B) when illuminated by ultraviolet radiation in the dark. 


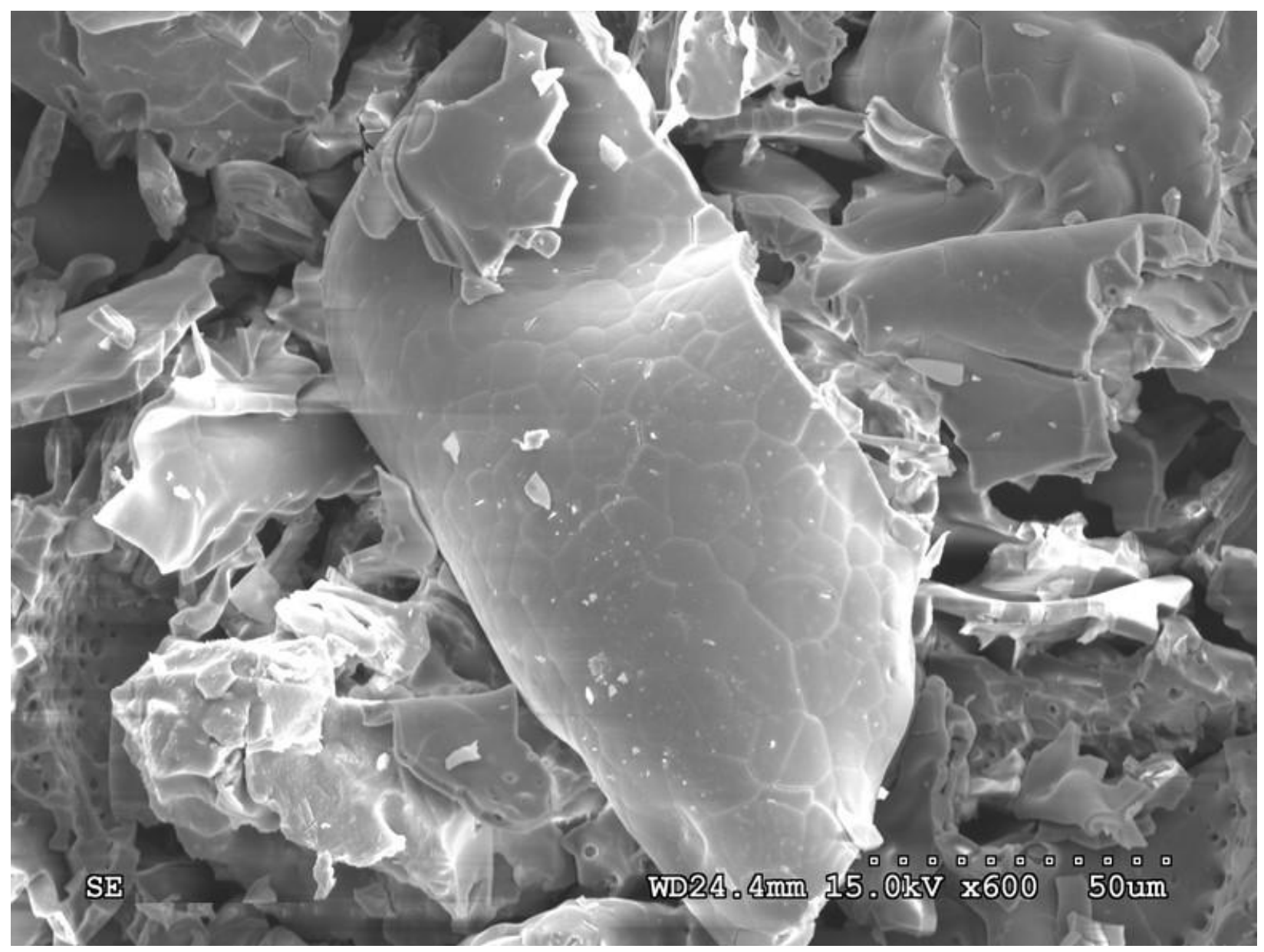

Fig. 2. (A) Low-resolution scanning electron micrograph of $\mathrm{Al}_{2} \mathrm{O}_{3}: \mathrm{Cr}$ combustion product 


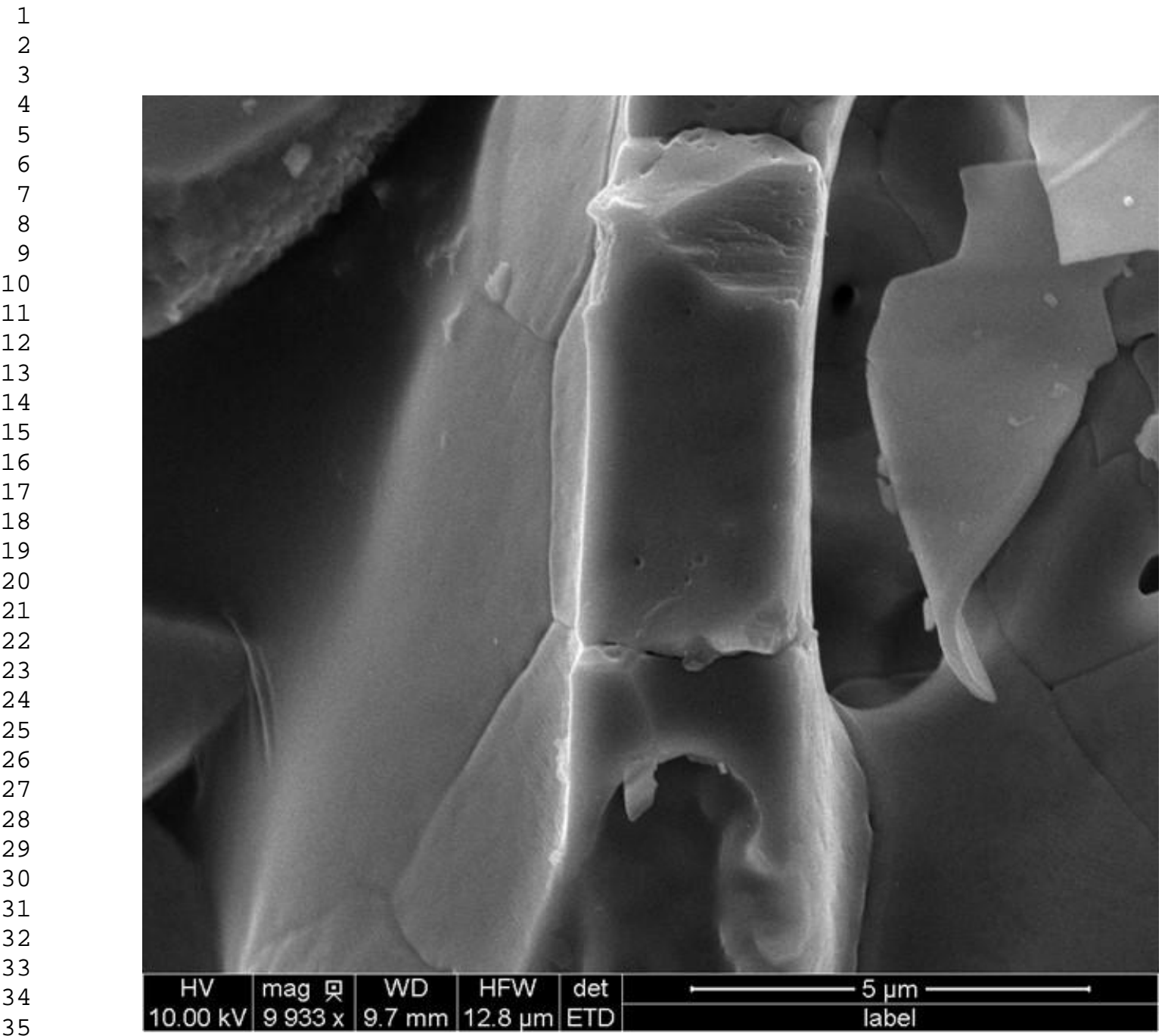

36

37

38

39

40

41

42

43

44

45

46

47

48

49

50

51

52

53

54

55

56

57

58

59

60

61

62

63

Fig. 2 (B) Scanning electron micrograph of $\mathrm{Al}_{2} \mathrm{O}_{3}: \mathrm{Cr}$ combustion product 


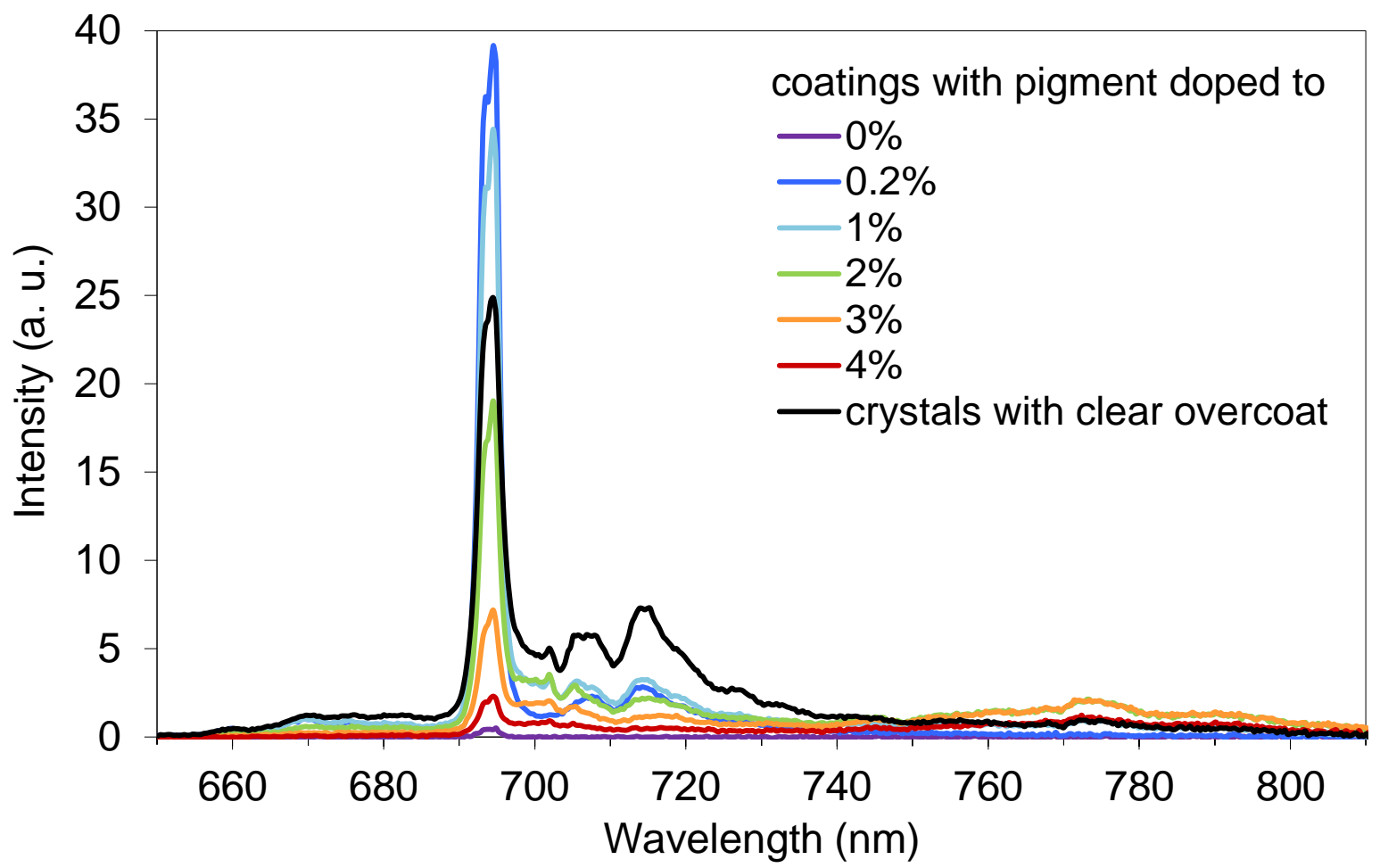

Fig. 3 (A) Spectral fluorescence of our samples. Percentages are the weight percent of $\mathrm{Cr}_{2} \mathrm{O}_{3}$ in the pigments 


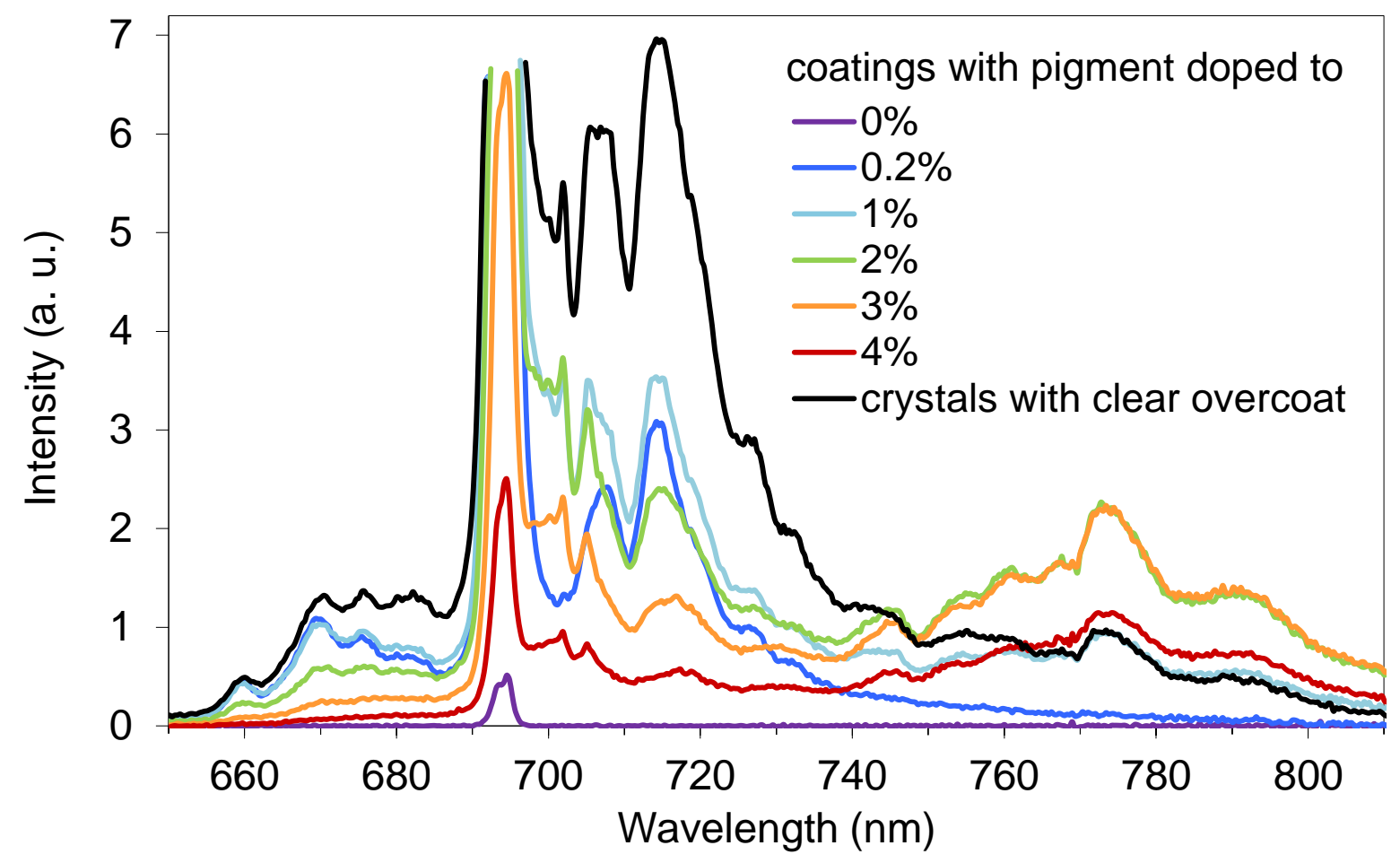

Fig. 3 (B) Details of fluorescence shown in Fig. 3 (A)

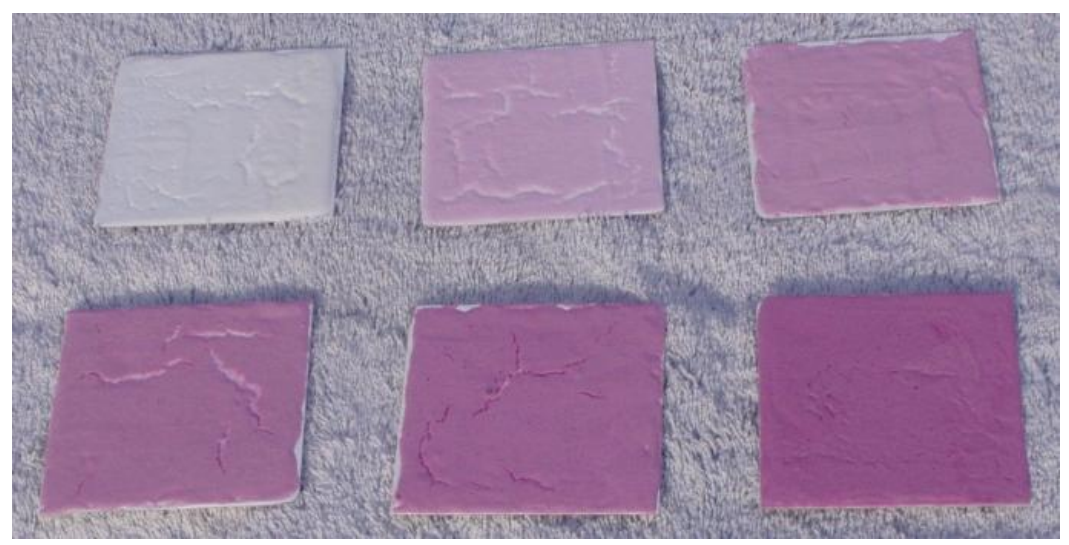

Fig. 4 (A) Coatings containing ruby powders with $0,0.2,1,2,3$, and $4 \%$ doping. The darker coatings contain pigments with more chromium. 


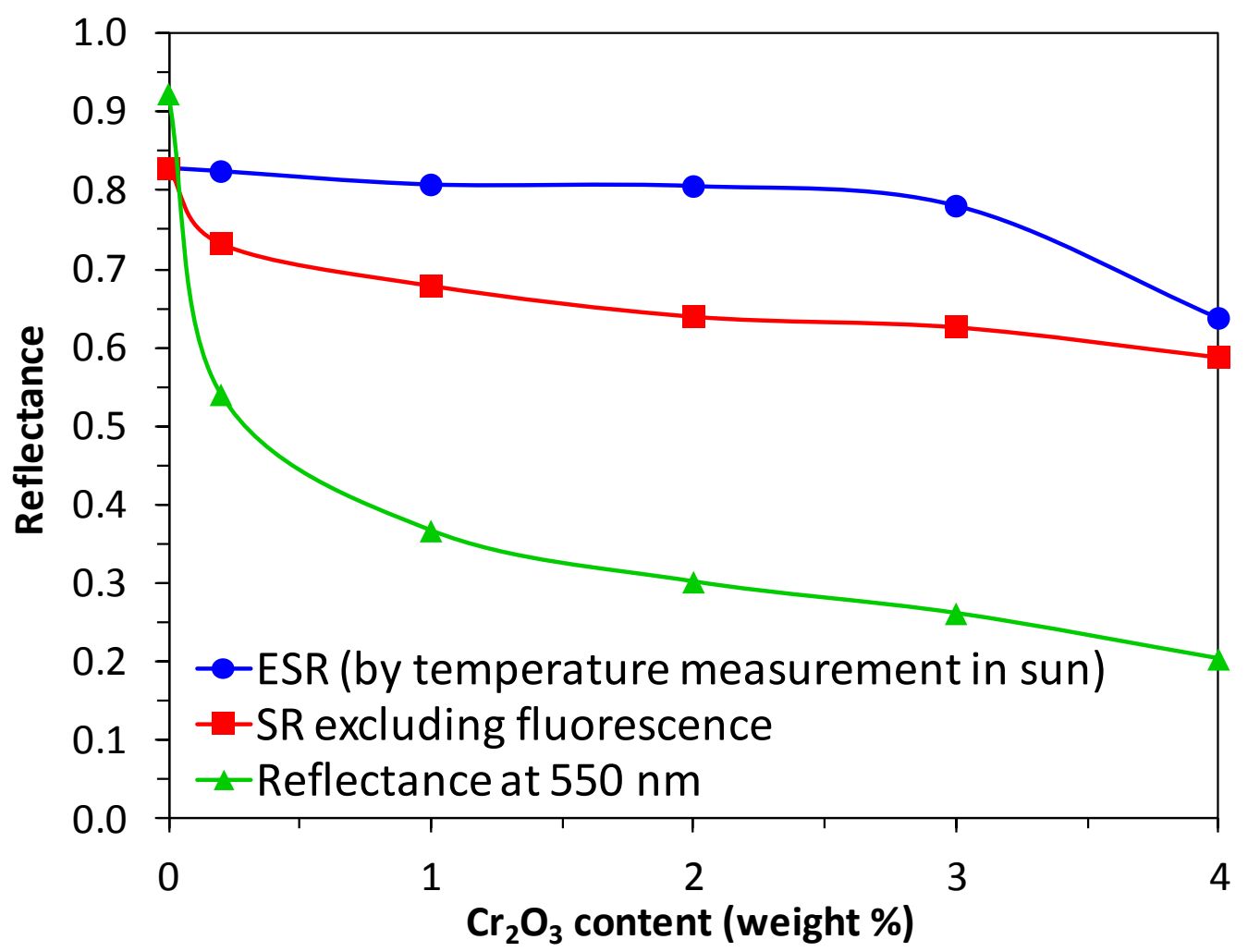

Fig. 4 (B) Effective Solar Reflectance (ESR), Solar Reflectance (SR) and visual brightness: reflectance at $550 \mathrm{~nm}$. 


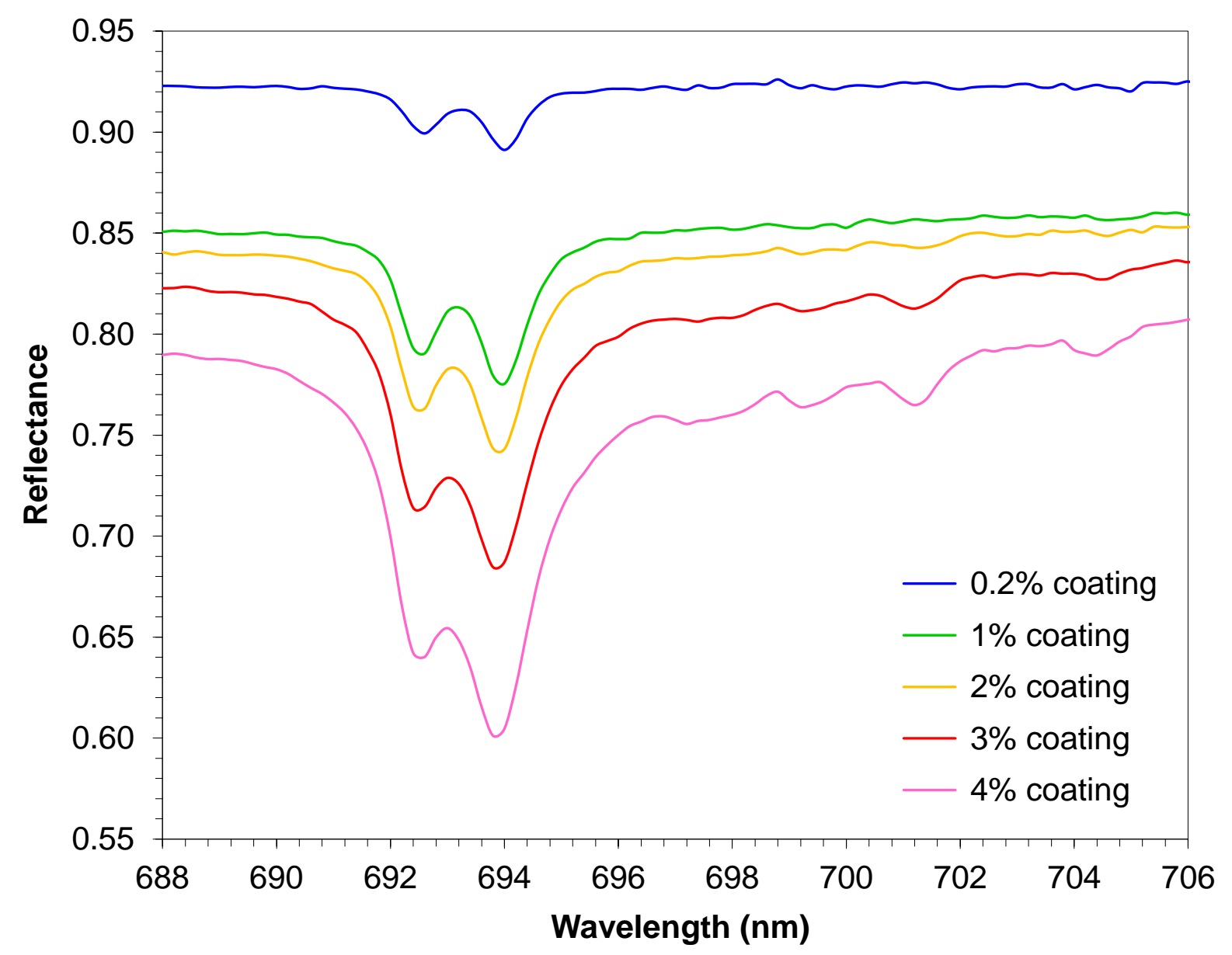

Fig. 5 High resolution reflectance spectra near the R-lines. In addition to spectral features, broadband absorption is present that increases with doping. 